\title{
Förster Resonance Energy Transfer Mediated Rapid and Synergistic Discrimination of Bacteria over Fungi using a Cationic Conjugated Glycopolymer
}

Sameer Hussain, ${ }^{a}$ Fengting Lv, ${ }^{a *}$ Ruilian Qi, ${ }^{a}$ Thangaraj Senthilkumar, ${ }^{a}$ Hao Zhao, ${ }^{a, b}$ Yanyan Chen, ${ }^{a, b}$ Libing Liu, ${ }^{a}$ and Shu Wang ${ }^{a, b}$

${ }^{a}$ Beijing National Laboratory for Molecular Sciences, Key Laboratory of Organic Solids, Institute of Chemistry, Chinese Academy of Sciences, Beijing, 100190, P. R. China

${ }^{\mathrm{b}}$ College of Chemistry, University of Chinese Academy of Sciences, Beijing 100049, P. R.

China

Email: lvft@iccas.ac.cn 


\section{Experimental}

Synthesis of compound 2: Compound 2 was prepared according to the reported procedure ${ }^{18}$. Compound 1 $(10 \mathrm{~g}, 80.27 \mathrm{mmol})$ and $\mathrm{NaI}(96.16 \mathrm{~g}, 642.16 \mathrm{mmol})$ were dissolved in acetone and kept for stirring at room temperature for $24 \mathrm{~h}$. Then, the solvent was removed under reduced pressure and reaction mixture was extracted with DCM/water thrice. After drying the organic layer using anhyd. $\mathrm{MgSO}_{4}$, the solvent was evaporated to get the pure product as pink color solution. ${ }^{1} \mathrm{H}$ NMR $\left(400 \mathrm{MHz}, \mathrm{CDCl}_{3}\right): \delta 3.74(\mathrm{~b}, 4 \mathrm{H}), 3.59$ $(\mathrm{t}, 2 \mathrm{H}), 3.26(\mathrm{t}, 2 \mathrm{H}), 2.24(\mathrm{~s}, 1 \mathrm{H})$. Mass (ESI-MS): calculated 239.0 (M+Na) ${ }^{+}$; observed 239.1.

Synthesis of compound 3: As the reported procedure, ${ }^{18}$ compound 2 (5.5 g, $\left.25.62 \mathrm{mmol}\right)$ and a-D-mannose pentaacetate $(2 \mathrm{~g}, 5.12 \mathrm{mmol})$ were dissolved in DCM $(30 \mathrm{ml})$ and placed in round bottom flask. To this, $\mathrm{BF}_{3}-\mathrm{Et}_{2} \mathrm{O}(3.63 \mathrm{~g}, 25.62 \mathrm{mmol})$ was added slowly and the reaction was stirred at room temperature for $48 \mathrm{~h}$. Then, the reaction mixture was poured into $5 \%$ aq. sodium bicarbonate $\left(\mathrm{NaHCO}_{3}\right)$ solution $(50 \mathrm{~mL})$. The organic layer was separated and washed further with $5 \%$ aq. $\mathrm{NaHCO}_{3}$ and excess water. After drying the organic layer with anhydrous $\mathrm{MgSO}_{4}$, the product was purified by column chromatography using 1:1 EtOAc/PE as eluent. The product was obtained as yellow oil. ${ }^{1} \mathrm{H}$ NMR (400 MHz, $\left.\mathrm{CDCl}_{3}\right): \delta 5.38-5.24$ (b, $3 \mathrm{H}), 4.88(\mathrm{~s}, 1 \mathrm{H}), 4.27(\mathrm{q}, 1 \mathrm{H}), 4.12(\mathrm{~d}, 2 \mathrm{H}), 3.84-3.66(\mathrm{~b}, 6 \mathrm{H}), 3.25(\mathrm{t}, 2 \mathrm{H}), 2.14(\mathrm{~s}, 3 \mathrm{H}), 2.09(\mathrm{~s}, 3 \mathrm{H}), 2.02$ (s, 3H), 1.97 (s, 3H). Mass (ESI-MS): calculated $568.3(\mathrm{M}+\mathrm{Na})^{+}$; observed 569.0.

Synthesis of compound 4: Compound 3 (1.24 g, $2.271 \mathrm{mmol})$ and $\mathrm{NaN}_{3}(1.47 \mathrm{~g}, 22.7 \mathrm{mmol})$ were transferred to a round bottom flask containing dry DMF. The reaction mixture was kept under stirring condition at room temperature for $24 \mathrm{~h}$. Thin layer chromatography was employed to monitor the completion of reaction. Afterwards, the reaction mixture was filtered out to remove sodium iodide formed during the reaction and any excess $\mathrm{NaN}_{3}$. The solvent was then removed under reduced pressure to get light 
yellow oily product. ${ }^{1} \mathrm{H}$ NMR (400 MHz, $\left.\mathrm{CDCl}_{3}\right): \delta 5.36-5.24(\mathrm{~b}, 3 \mathrm{H}), 4.86(\mathrm{~s}, 1 \mathrm{H}), 4.28(\mathrm{q}, 1 \mathrm{H}), 4.01$ (d, 2H), $3.82(\mathrm{~m}, 1 \mathrm{H}), 3.65(\mathrm{~m}, 5 \mathrm{H}), 3.37(\mathrm{t}, 2 \mathrm{H}), 2.13(\mathrm{~s}, 3 \mathrm{H}), 2.08(\mathrm{~s}, 3 \mathrm{H}), 2.01(\mathrm{~s}, 3 \mathrm{H}), 1.97(\mathrm{~s}, 3 \mathrm{H})$. Mass (MALDI-TOF): calculated $484.2(\mathrm{M}+\mathrm{Na})^{+}$; observed 483.8 .

Synthesis of compound 7: Compound $6(3.2 \mathrm{~g}, 5.16 \mathrm{mmol})$ was dissolved in dry THF and transferred to a two neck round bottom flask. To this, $\mathrm{NaH}(1.23 \mathrm{~g}, 51.6 \mathrm{mmol})$ was added and the reaction mixture was kept for stirring under inert atmosphere for $30 \mathrm{~min}$. Propargyl bromide $(1.41 \mathrm{~g}, 11.86 \mathrm{mmol})$ was then added to the flask slowly and the reaction was further stirred overnight at room temperature. The salts were filtered out and the solvent was removed under reduced pressure. The product was obtained as white powder after purification via column chromatography using 1:1 EtOAc/PE as eluent. ${ }^{1} \mathrm{H}$ NMR $(400 \mathrm{MHz}$, $\left.\mathrm{CDCl}_{3}\right): \delta 7.15(\mathrm{~s}, 2 \mathrm{H}), 4.20(\mathrm{~s}, 4 \mathrm{H}), 4.12(\mathrm{t}, 4 \mathrm{H}), 3.87(\mathrm{~m}, 4 \mathrm{H}), 3.75(\mathrm{~m}, 4 \mathrm{H}), 3.67(\mathrm{~m}, 20 \mathrm{H}), 2.42(\mathrm{~s}, 2 \mathrm{H})$. Mass (ESI-MS): calculated 719.1 (M+Na) ${ }^{+}$; observed 719.0.

Preparation of microorganism suspensions: A single colony of $\mathrm{Amp}^{\mathrm{r}}$ E.coli (Top 10) was transferred from solid Luria-Bertani (LB) agar plate to liquid LB medium $(10 \mathrm{~mL})$ containing $50 \mu \mathrm{g} / \mathrm{mL}$ ampicillin, and cultured for $12 \mathrm{~h}$ at $37^{\circ} \mathrm{C}$. Similarly, other microbes, viz. S. aureus (ATCC6538) from solid nutrient broth (NB) agar plate, C. albicans (CA10231) from solid yeast-extract peptone dextrose (YPD) agar plate, P. aeruginosa (JCM5962) from LB agar plate and S. cerevisiae (P11) from YPD agar plate were transferred to liquid NB, YTD, LB and YPD media, respectively. The bacteria S. aureus and P. aeruginosa were cultured for $12 \mathrm{~h}$ at $37^{\circ} \mathrm{C}$. Fungi C. albicans were cultured for $12 \mathrm{~h}$ at $27^{\circ} \mathrm{C}$. The microbes were then harvested by centrifugation at $7200 \mathrm{rpm}$ for 2 min and washing with 1X PBS three times. Later, the microbes were resuspended in $1 \mathrm{X}$ PBS and diluted accordingly to obtain desirable optical density (OD) at $600 \mathrm{~nm}$. 
Zeta-potential measurements: The polymer PFBTM-NMe ${ }^{+}(25 \mu \mathrm{M})$ was added to the suspension of each microbe $\left(\mathrm{OD}_{600}=0.2\right.$ for $E$. coli and $S$. aureus, $\mathrm{OD}=0.5$ for $C$. albicans) in $1 \mathrm{ml} 1 \mathrm{X}$ PBS. After incubation for $2 \mathrm{~min}$ at room temperature, each microorganism suspension was centrifuged at $8500 \mathrm{rpm}$ for $3 \mathrm{~min}$ followed by washing with $1 \mathrm{X}$ PBS to remove any unbound polymer. Each microorganism was then suspended in $1 \mathrm{~mL}$ of sterile water for measuring zeta-potential. 

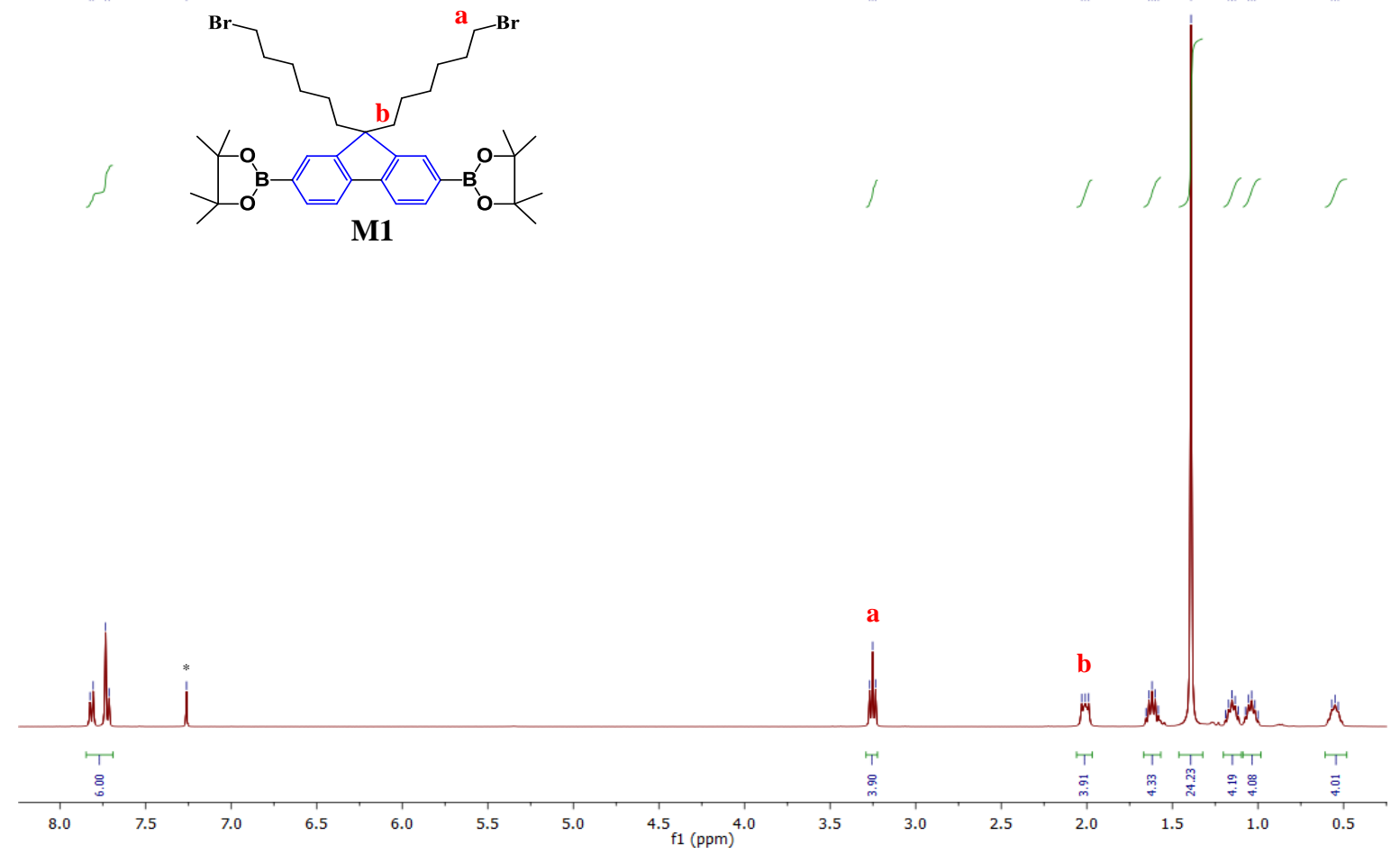

Figure S1. ${ }^{1} \mathrm{H}-\mathrm{NMR}$ spectrum of monomer $\mathbf{M 1}$ in $\mathrm{CDCl}_{3}$.

$\stackrel{8}{i}$<smiles>OCCOCCI</smiles>

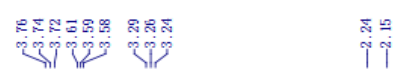

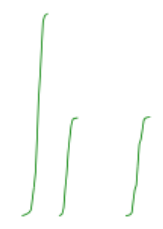

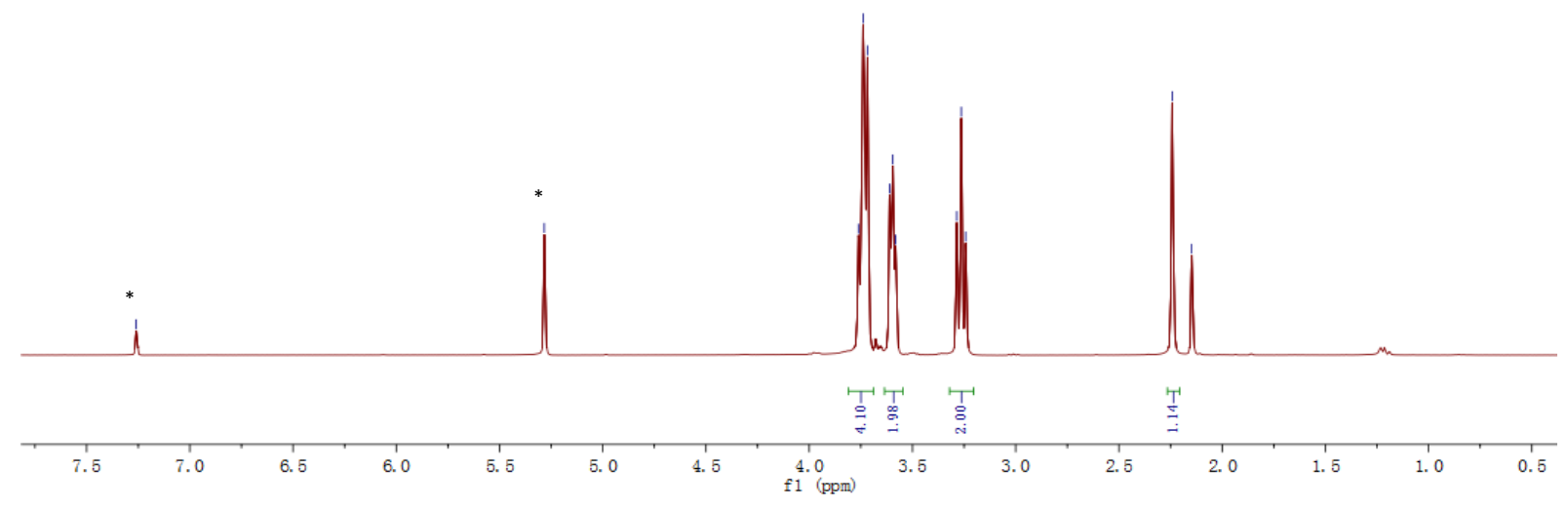

Figure S2. ${ }^{1} \mathrm{H}-\mathrm{NMR}$ spectrum of compound 2 in $\mathrm{CDCl}_{3}$. 


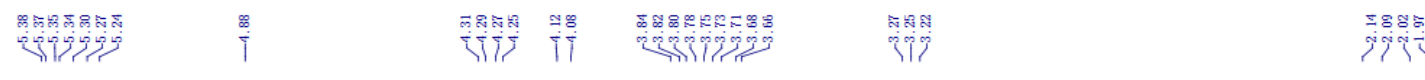

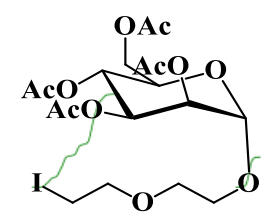

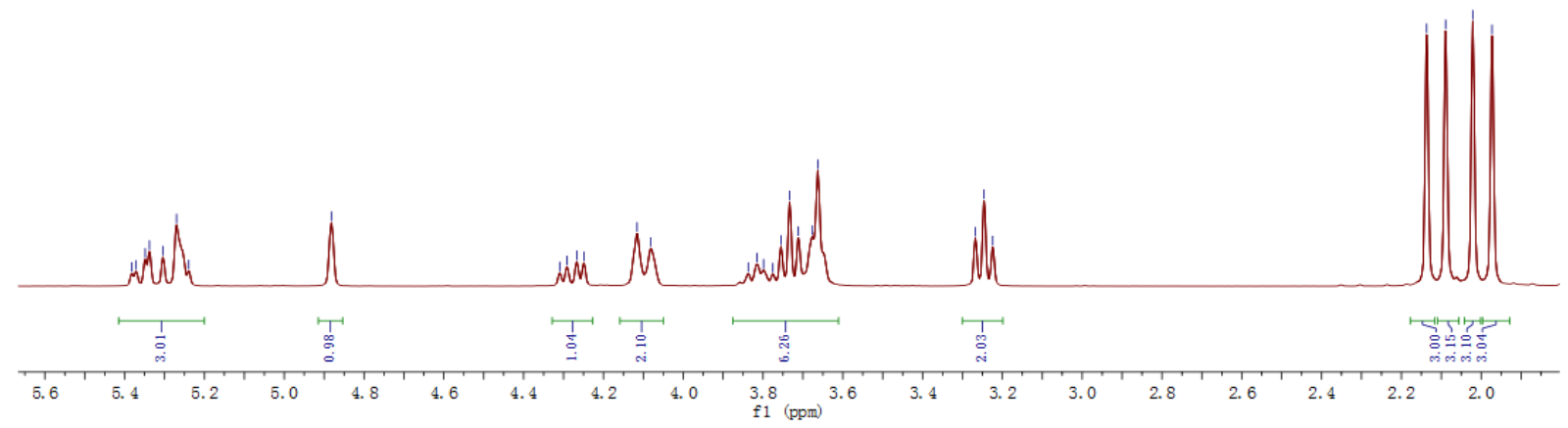

Figure S3. ${ }^{1} \mathrm{H}-\mathrm{NMR}$ spectrum of compound 3 in $\mathrm{CDCl}_{3}$.

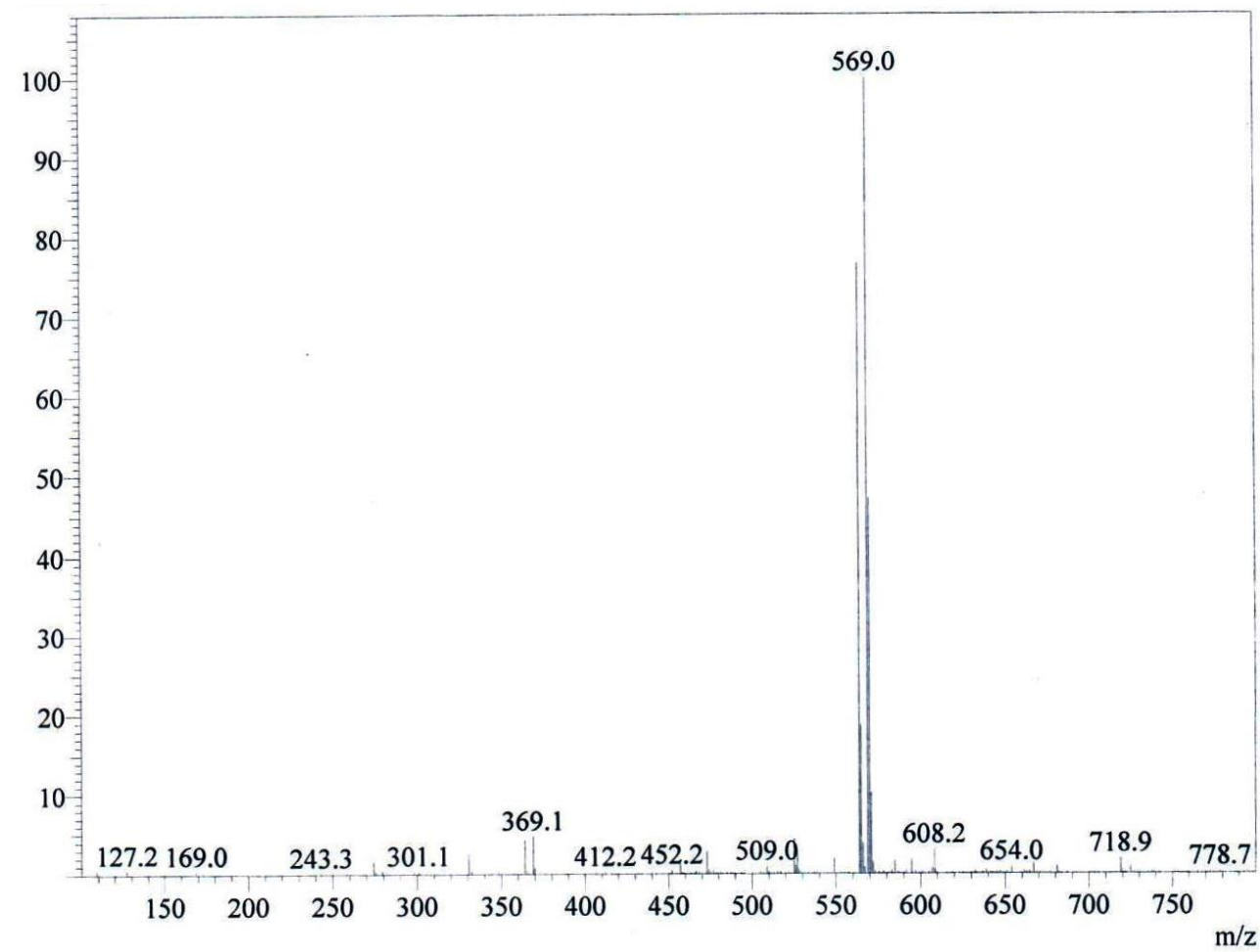

Figure S4. ESI-MS spectrum of compound 3. 


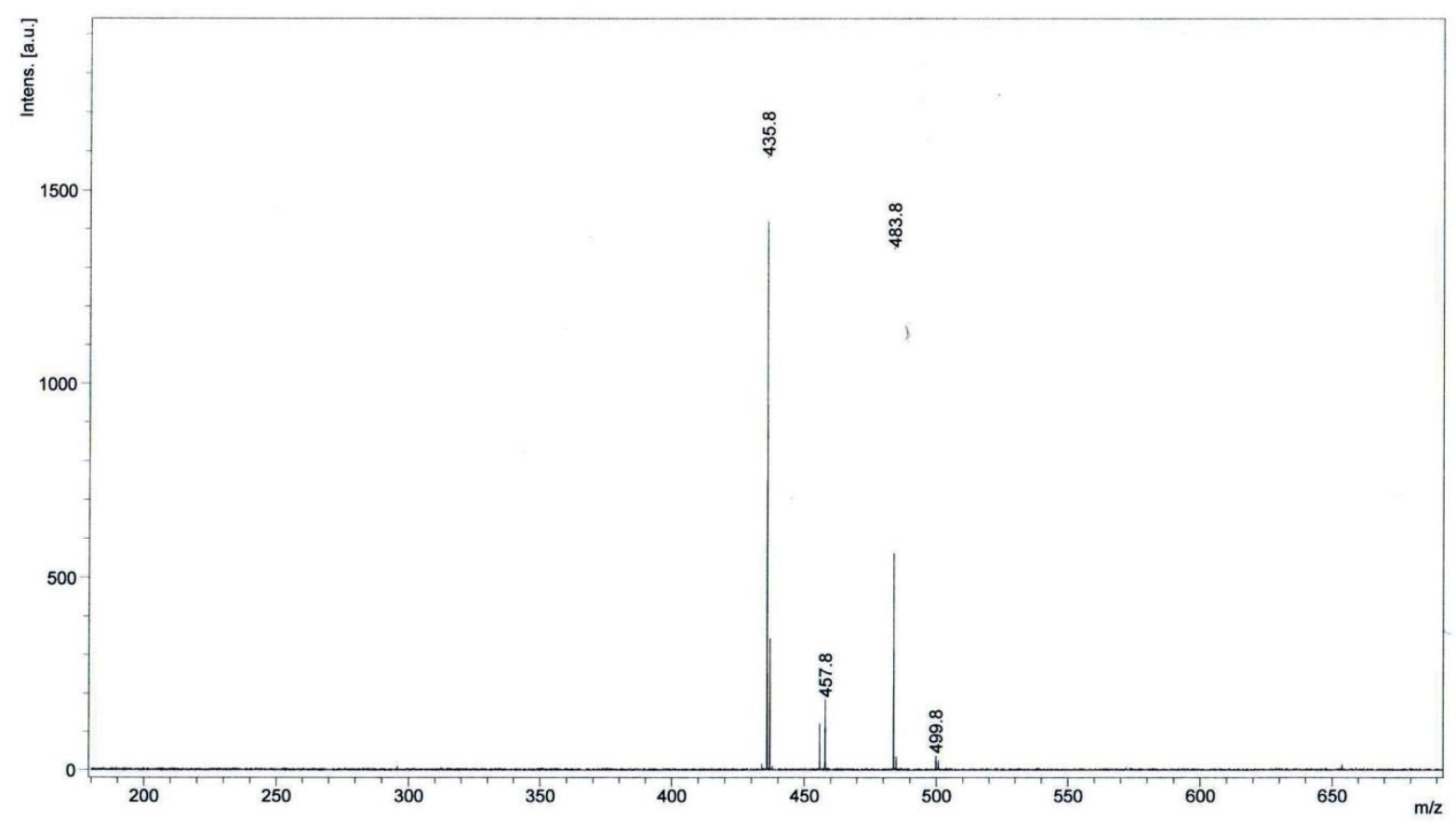

Figure S5. MADLI/TOF spectrum of compound 4.

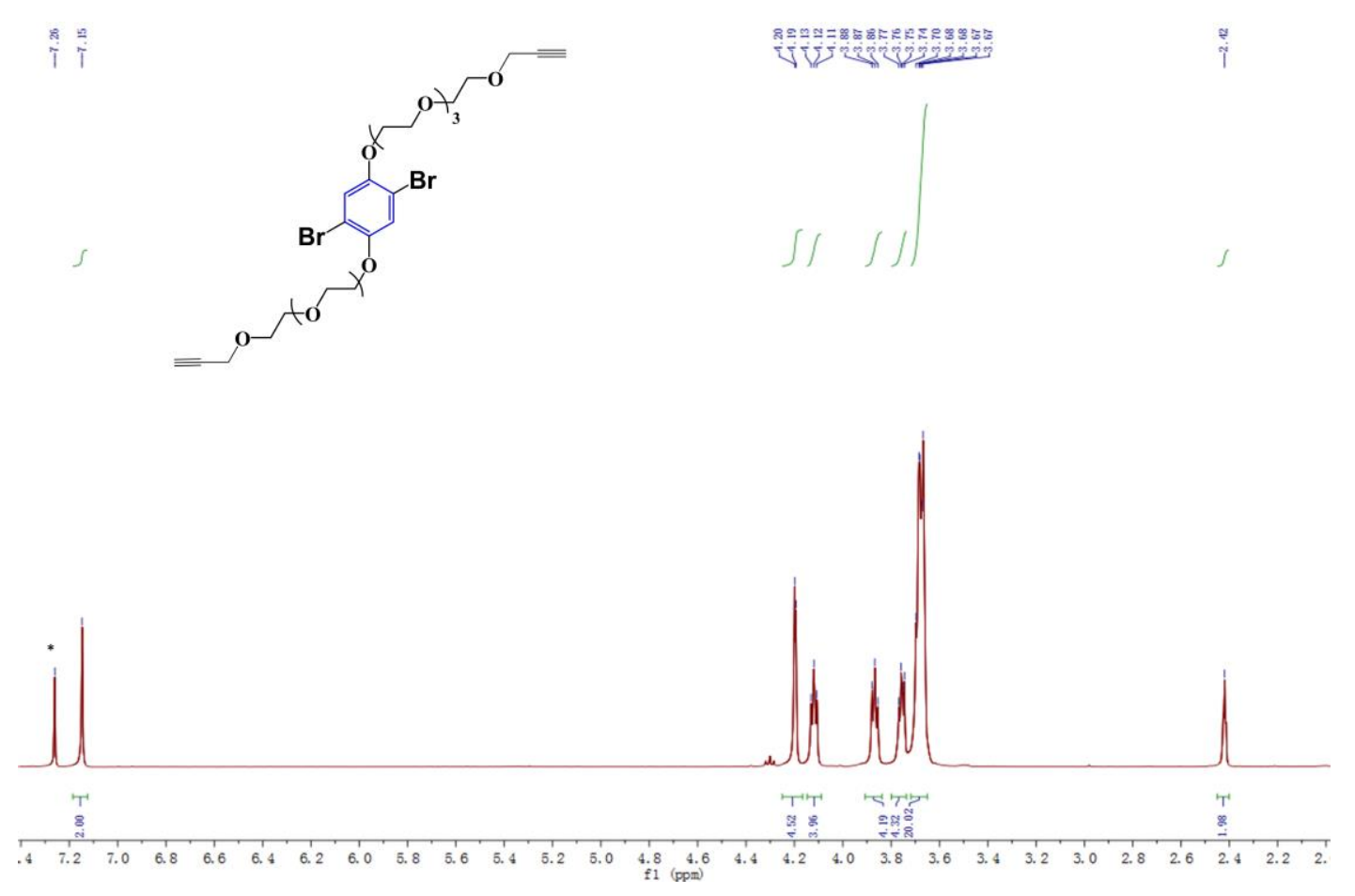

Figure S6. ${ }^{1} \mathrm{H}-\mathrm{NMR}$ spectrum of compound 7 in $\mathrm{CDCl}_{3}$. 


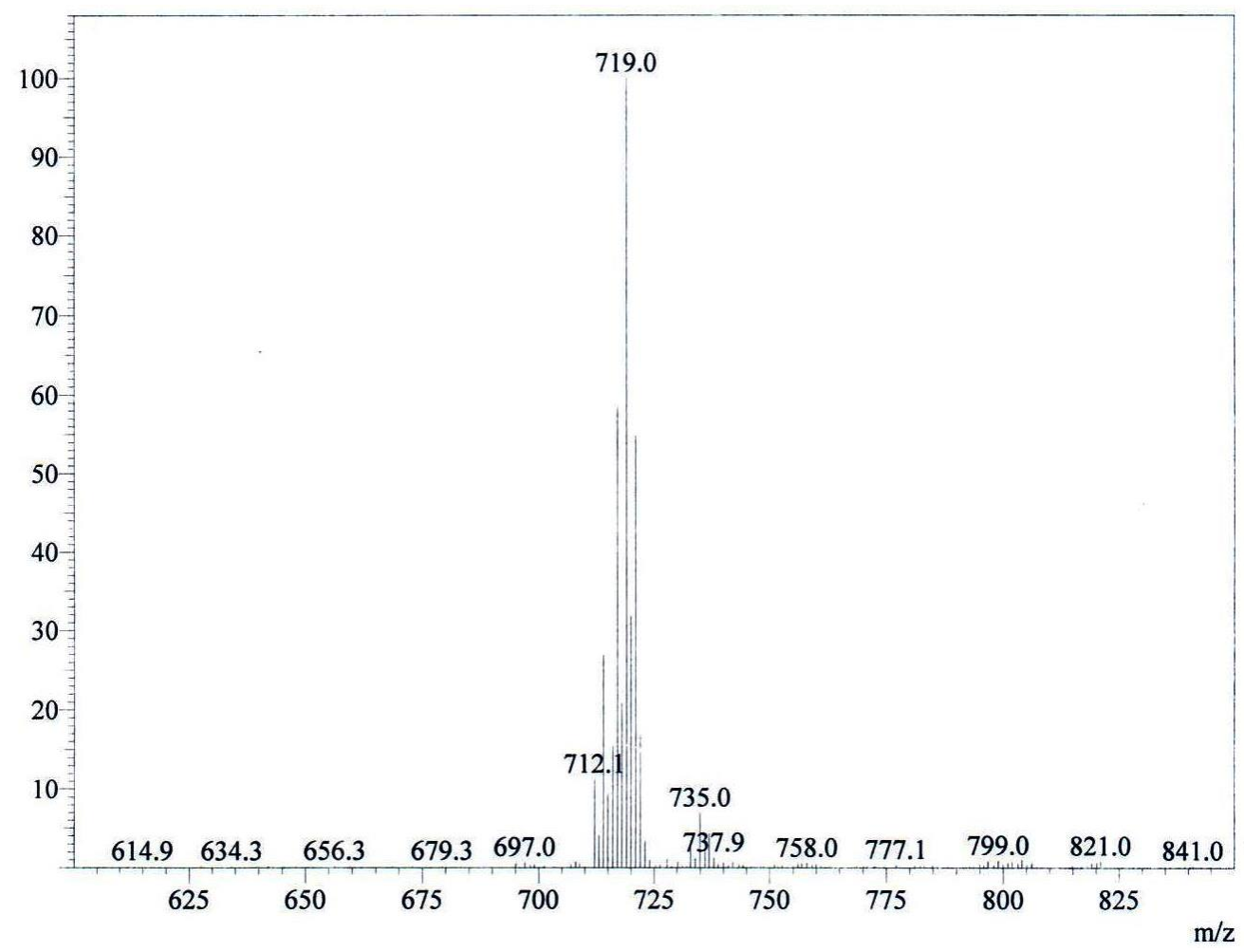

Figure S7. ESI-MS spectrum of compound 7.

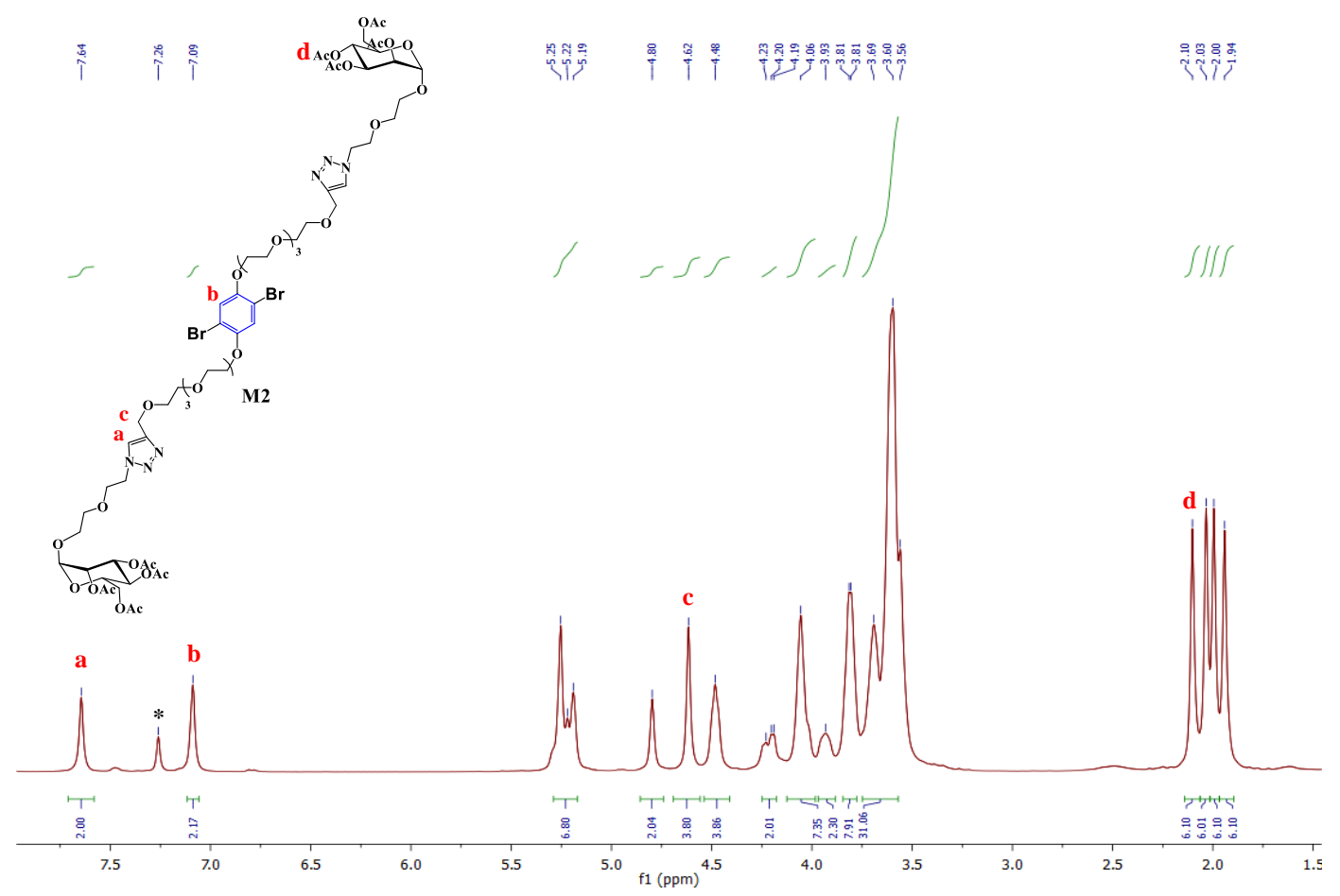

Figure S8. ${ }^{1} \mathrm{H}-\mathrm{NMR}$ spectrum of monomer $\mathbf{M} 2$ in $\mathrm{CDCl}_{3}$. 


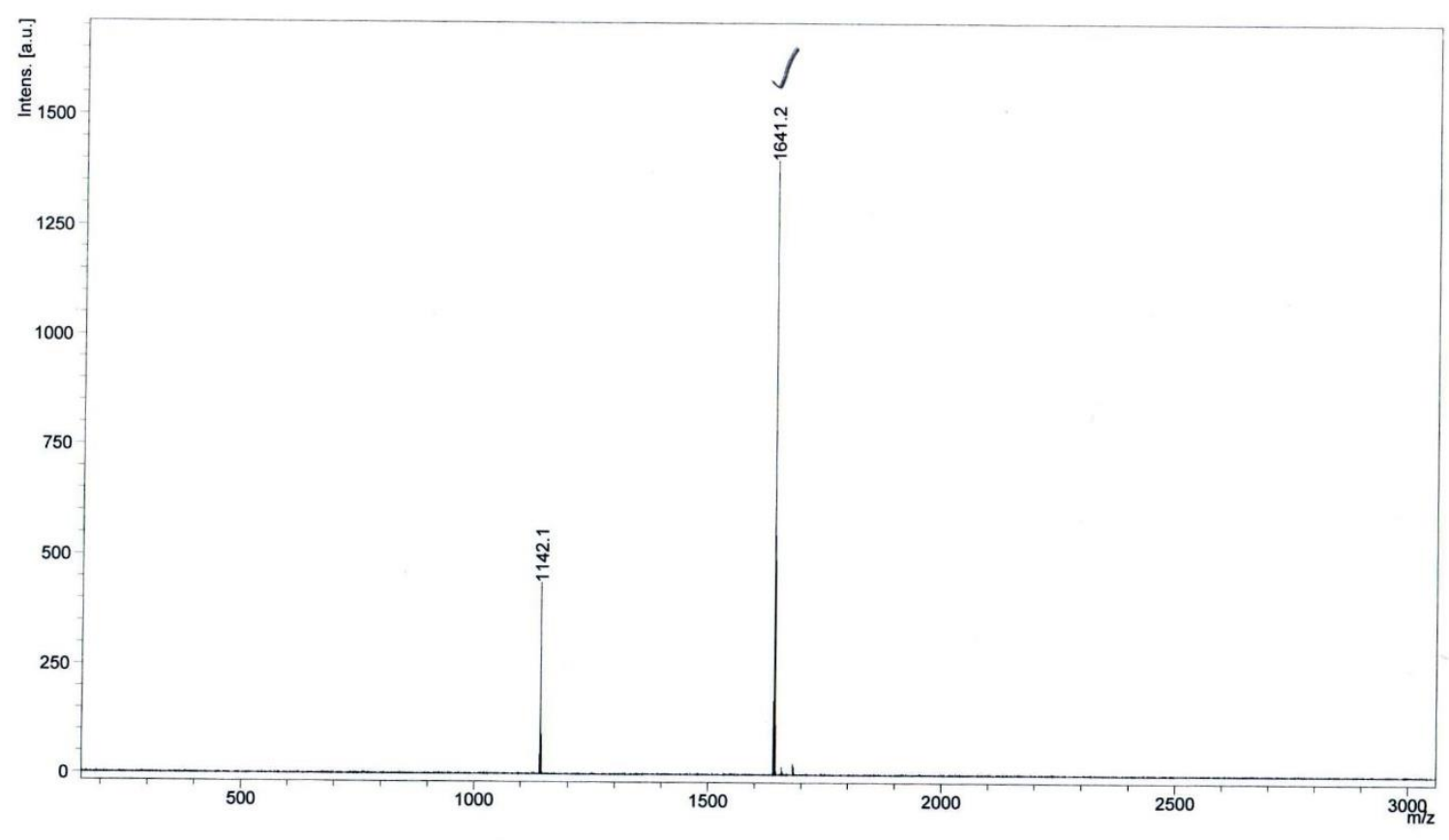

Figure S9. MALDI/TOF spectrum of monomer M2.

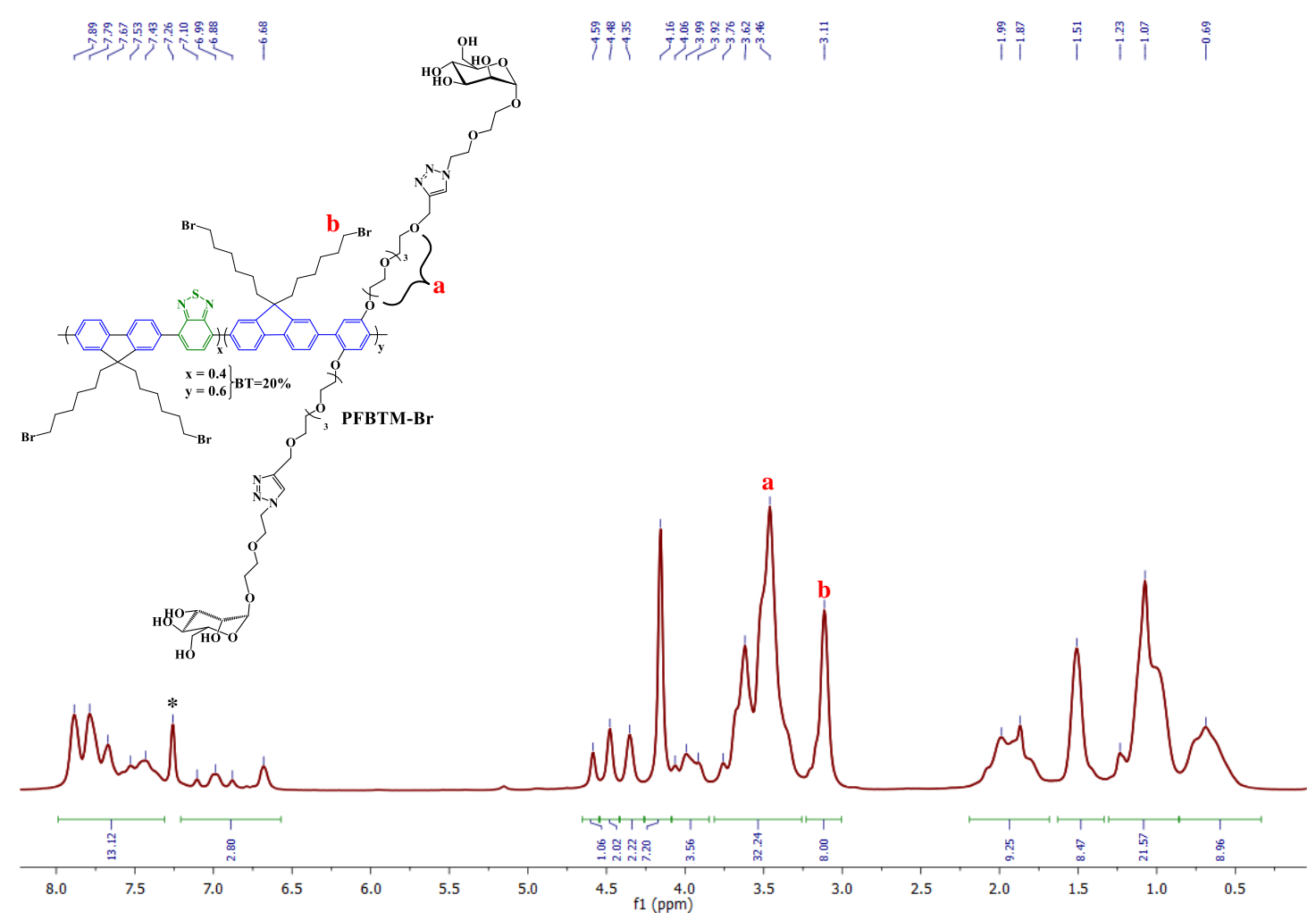

Figure S10. ${ }^{1} \mathrm{H}-\mathrm{NMR}$ spectrum of polymer PFBTM-Br in $\mathrm{CDCl}_{3}$. 


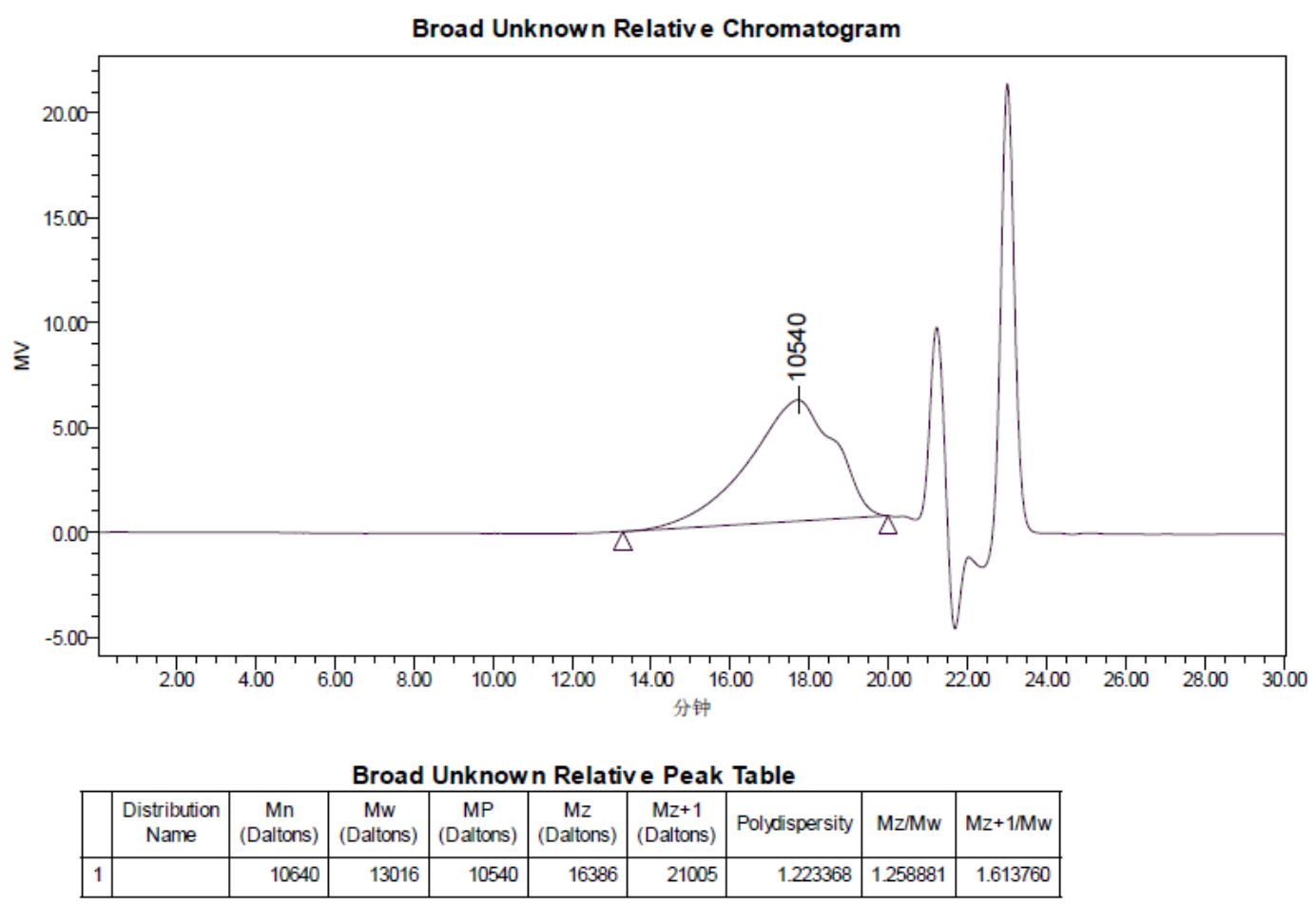

Figure S11. GPC chromatogram of polymer PFBTM-Br in DMF using polystyrene standard.

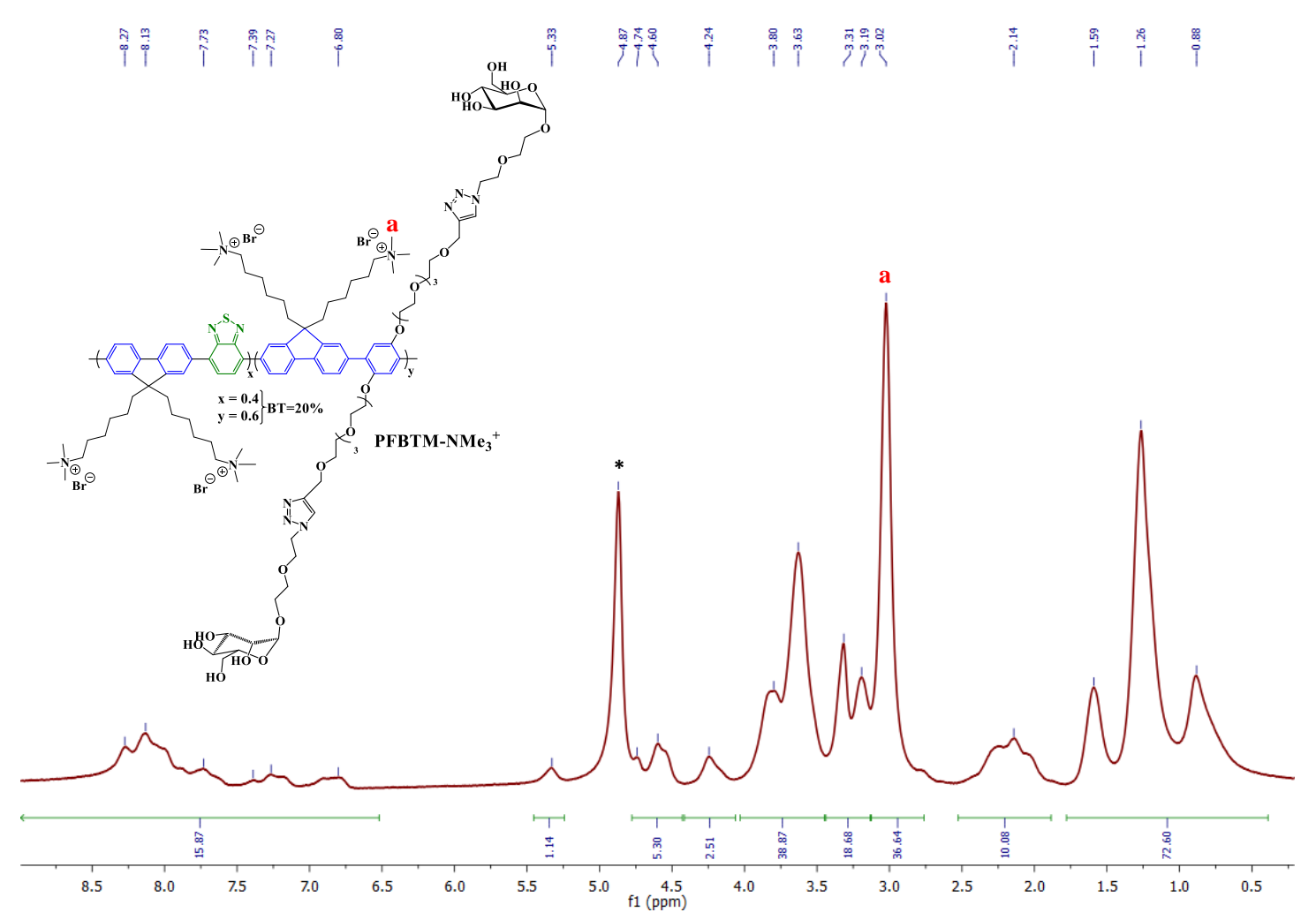

Figure S12. ${ }^{1} \mathrm{H}-\mathrm{NMR}$ spectrum of polymer PFBTM-NMe ${ }_{3}{ }^{+}$in $\mathrm{CD}_{3} \mathrm{OD}$. 


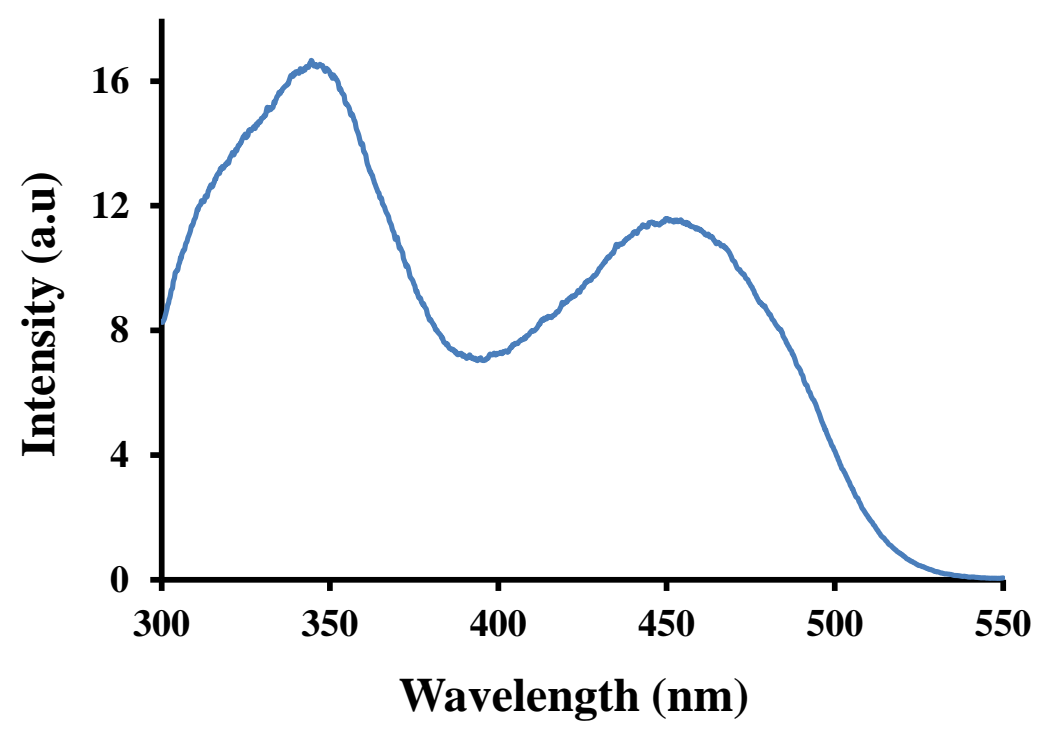

Figure S13. Excitation spectra of PFBTM-NMe ${ }_{3}^{+}$at emission wavelength of $555 \mathrm{~nm}$.

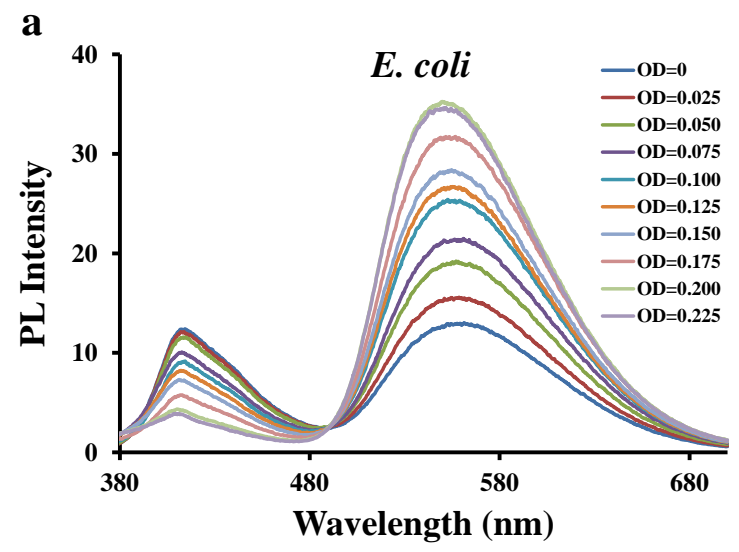

b

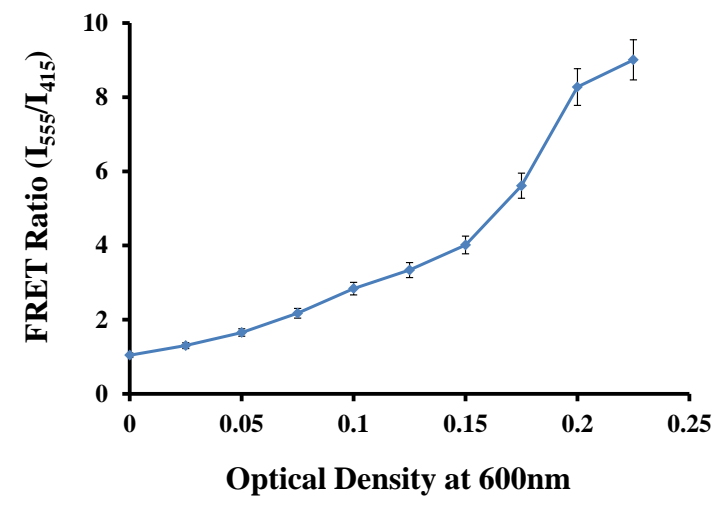

Figure S14 a) Change in emission spectra of PFBTM-NMe ${ }_{3}^{+}$with different optical density of E. coli. Each measurement was recorded after 2 min of incubation. b) Corresponding change in the FRET ratio with different optical density of $E$. coli. 


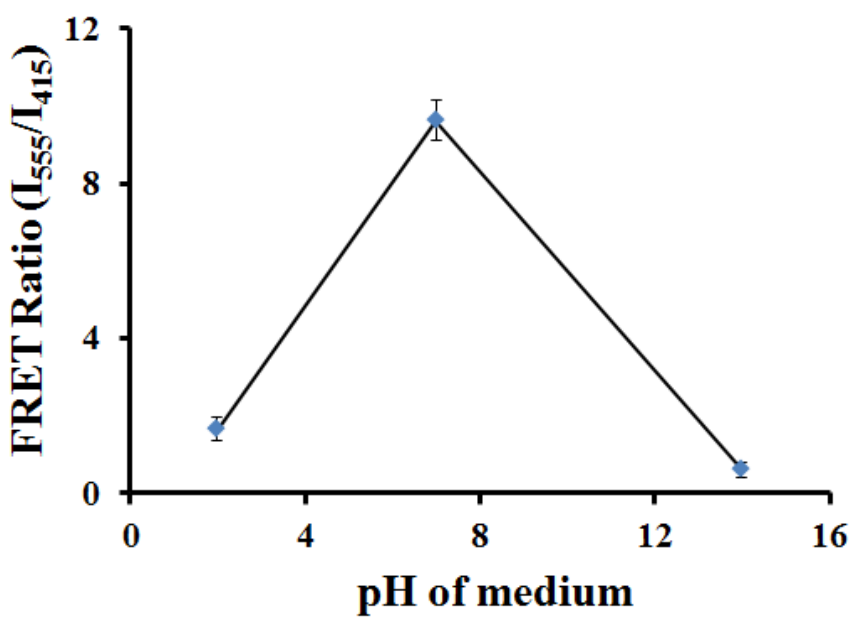

Figure S15. Effect of $\mathrm{pH}$ on FRET efficiency for gram negative bacteria E. coli using polymer PFBTM-NMe $3^{+}$.
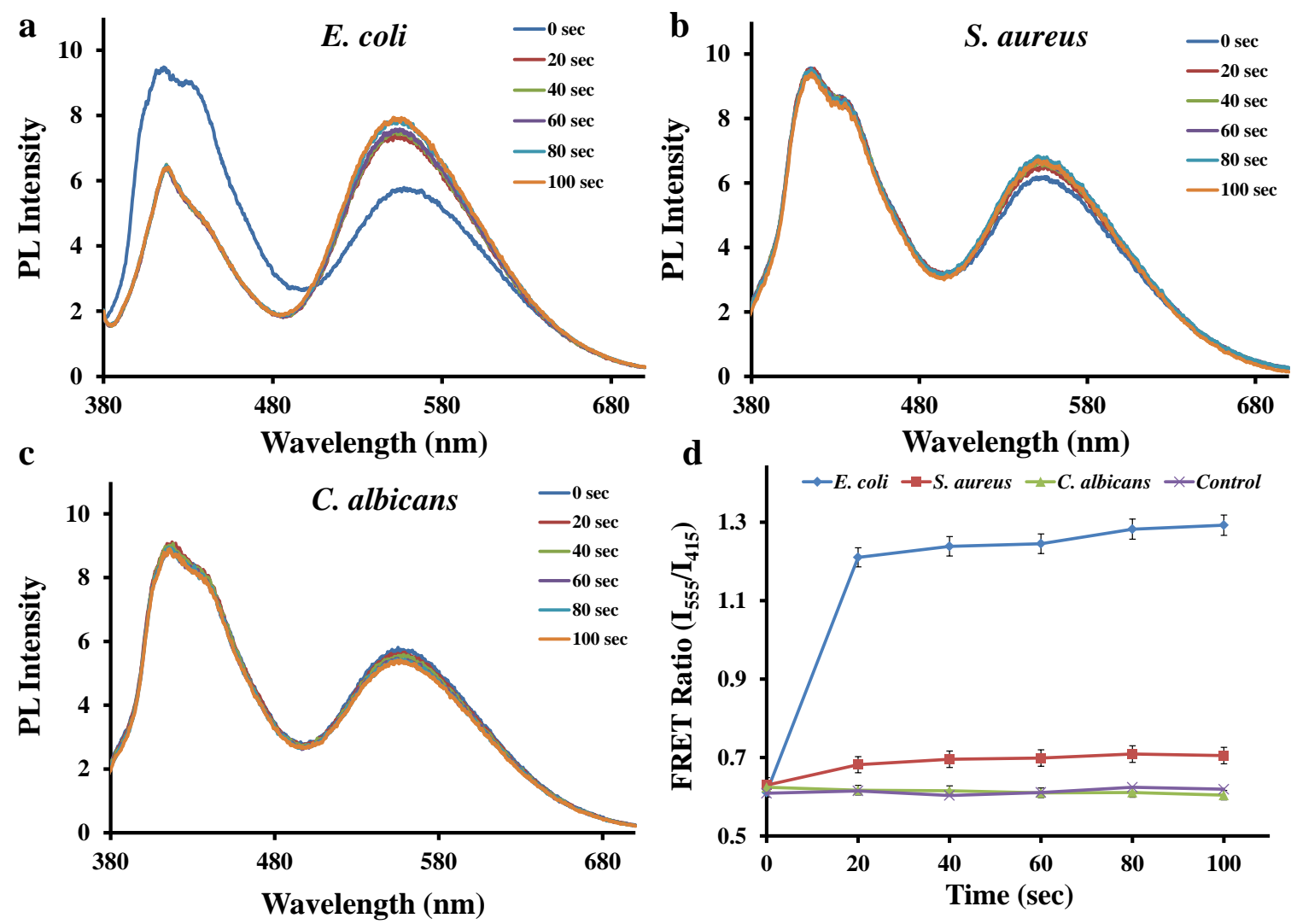

Figure S16 Change in emission spectra of control polymer PFBTM-Br with a) E. coli, b) $S$. aureus and c) C. albicans at different time intervals. d) Corresponding change in the FRET ratio for each microorganism. The optical density (OD) for each microorganism was 0.2. 